\title{
The association between tobacco use and perceptions of tobacco price strategies within primary care patients in rural Greece
}

Emmanouil Symvoulakis ${ }^{1}$, Spyridon Klinis ${ }^{2}$, Nikolaos Kakoliris $^{1}$, Despoina Karamitrou ${ }^{2}$, Constantine Vardavas ${ }^{1}$, Christos Lionis $^{1}$

\begin{abstract}
BACKGROUND Tobacco use is a detrimental public health issue associated with a plethora of adverse health outcomes. The purpose of this report was to investigate the association between tobacco use and perceptions of tobacco price strategies to reduce consumption in a rural primary care setting in Northern Greece.

METHODS The study took place within a primary care setting, in Alonakia, in Northern Greece within a primary health care setting. Consecutive patients who were current smokers $(n=121)$ with a routine appointment for any reason were invited to participate over a 6-week period, during the second semester of 2013.

RESULTS The mean daily cigarette consumption was $20.2 \pm 12.4$ (range: 2-60) and their pack/year consumption was $31.8 \pm 30.4$ (range: $1-150$ pack/years). Within the context of a regression analysis, the likelihood for patients who were smokers to positively respond that the cost of tobacco has an effect on their daily cigarette consumption was found to decrease by $3 \%$ for every cigarette smoked more per day and by $2 \%$ for every more pack/year. Furthermore, the likelihood for participants to report that they would quit smoking in case of a doubling in the price of tobacco products decreased by $5 \%$ for every cigarette smoked more per day.

concLusions The above findings imply that the reduction in tobacco use in rural Greece, is complex and a population's sensitivity should be enhanced through primary care initiatives that are adjusted between health promotion and counseling in conditions of socioeconomic distress.
\end{abstract}

AFFILIATION

1 Department of Social

Medicine, Clinic of Social and Family Medicine,

University of Crete, Greece

2 Primary Care Setting of Siatista, Greece

\section{CORRESPONDENCE TO}

Emmanouil Symvoulakis, Department of Social Medicine, Clinic of Social and Family Medicine,

University of Crete, Greece,

University

of Crete, 71003 Heraklion,

Greece email:

symvouman@yahoo.com

\section{KEY WORDS}

tobacco cost, attitudes, beliefs, smoking cessation, economic crisis

\section{BACKGROUND}

Tobacco use is one of the most detrimental public health issues, associated with a plethora of adverse health outcomes and with a serious impact on the cost of health care services ${ }^{1}$. This becomes more evident especially in periods of economic crisis, where health systems are seriously challenged from budget cuts and austerity measures. On one hand, tobacco may be responsible for substantial constraint on the health care system, as in the case of Greece, while on the other the tobacco industry, continues to maximize their profits, despite the harmful effect of their products both to health and countries' health system expenditure ${ }^{2,3}$. Several measures have been proposed to control the global tobacco epidemic and among which an increase in tobacco product price through taxation has been suggested as one of the most effective $e^{4-6}$.

Tobacco tax increases have been shown to have a positive effect on smoking cessation and in increasing quit attempts ${ }^{7-}$
${ }^{10}$. Nevertheless, price increases should not be considered as a unique policy for reducing consumption, as the impact of personal income, advertising and health promotion also contribute $^{11}$. Especially, in the case of Greece, consecutive attempts over time for increased taxation of tobacco products have not yielded any dramatic improvement in smoking cessation rates as indicated by the high prevalence of smokers in the country. Greek people seem to be "price-resistant" but agree to increased taxation on tobacco products, despite the overall national economic restriction, given that this is earmarked for the health care system ${ }^{5}$. It is important to note that people in rural areas, due to the geographical morphology in Greece, usually have limited access to illicit tobacco markets. Illicit trade is common in urban areas, outdoor markets, near border areas and ports and is popular to immigrant population ${ }^{12}$. Even though Greece due to its location constitutes a pathway for tobacco smuggling towards 
the Western European countries, according to a recent study, seems to have the lowest prevalence $(1 \%)$ in the identification of illicit packs among eighteen European countries ${ }^{13}$.

With the above in mind, the aim of this study was to assess the association between future tobacco use in relation to price strategies to reduce consumption, in the midst of an intense financial crisis, from a rural primary care setting in Greece.

\section{METHODS}

The study took place within a primary care setting, in Alonakia, in Northern Greece. Consecutive patients-smokers with a routine appointment for any reason were invited to participate over a 6-week period, during the second semester of 2013. One hundred and twenty-one patients-smokers participated in the survey, 83 males and 38 females with a mean age of 53.2(SD 15.6) years (range: 17-88 years). Seventy-two participants (59.5\%) reported a net income of $500 €$ and less per month. Ethics approval was obtained from the Ethics Committee of Kozani General Hospital, while each participant provided written informed consent.

An original questionnaire of ten items was designed including domains on patients' attitudes and concerns towards tobacco use. The instrument was developed based on GPs' observations during regular visits in regards to smoking habit and local community-widespread views on financial crisis and its possible impact on tobacco use. A GP, not affiliated with the recruitment unit, reviewed the instrument and offered feedback. Clarity and relevance of the content were checked by testing the questionnaire among 10 respondents. Demographic data (age, sex, marital status, education, occupation and monthly income) were also collected.

The statistical analyses were performed with SPSS 20.0. Descriptive analyses were used, while a univariate logistic regression was applied to determine the association between tobacco use parameters and support for increase in tobacco taxation for which odd ratios and 95\% confidence intervals ( $95 \%$ C.I) were also presented.

\section{RESULTS}

The mean daily cigarette consumption of the respondents was 20.2(SD 12.4) (range: 2-60) and their average pack/year consumption was 31.8(SD 30.4) (range: 1-150 pack/years). Moreover, $61.2 \%$ declared an intention to quit tobacco use during the next 12 months. Most patients-smokers (87, $71.9 \%$ ) had made one or more quit attempts in the past, but only $8(6.6 \%)$ sought personalized medical assistance to do so. Amongst participants, the most important self-reported rational for intending to quit were potential health effects
[60/74, (81.1\%)], while the cost of tobacco was reported as a reason to quit by $7 / 74(9.5 \%)$ of those who intended to quit in the next year. Even though, $52 \%$ of smokers declared that the cost of tobacco affects their daily cigarette consumption, $63.6 \%$ of respondents reported no intention to quit, even if tobacco product prices were to double.

Within a univariate regression analysis, the likelihood for participants to positively answer that tobacco cost has an effect on their daily cigarette consumption decreased by $3 \%$ for every increase of one cigarette smoked per day [Odds Ratio (OR): 0.97, 95\% Confidence Interval (CI): 0.94-1.00, p=0.032] and by $2 \%$ for every one unit increase in the pack/year history of smoking (OR: 0.98, 95\% CI: 0.96-0.99, $\mathrm{p}=0.0039$ ). Furthermore, the likelihood for participants to report an intention to quit smoking if tobacco prices would double, decreased by $5 \%$ for every cigarette smoked more per day (OR: 0.95, 95\% CI: 0.92-0.98, $\mathrm{p}=0.0017$ ).

\section{DISCUSSION}

This regional study indicated an association between the number of cigarettes smoked per day and pack/year history, with reduced intention to give up smoking in case of tobacco price duplication. This finding stresses the importance of patient counseling to reduce tobacco use, as national policies may not have the ideal outcome if not supported at the grassroots level. It is through this level that the primary health care providers can offer valuable assistance and discuss tobacco use with their patients within their daily clinical practice.

Primary care makes up a promising field for the development of smoking cessation interventions ${ }^{14}$. General practitioners (GPs) have a unique opportunity to influence national smoking rates $^{15}$, through the implementation of effective primary care interventions ${ }^{16}$, but may still handle poorly smoking cessation counseling ${ }^{15,17}$. Regular healthcare visits, continuity of care and doctor-patient relationship, constitute strong elements for a successful smoking cessation intervention. Towards this direction, smoking cessation programmes, in conjunction with the clinical services offered, should be integrated in primary $\operatorname{care}^{18}$. Of course the number of smokers who state that they have received an evidence-based approach from their primary care physician in order to quit smoking remains low $^{19,20}$, particularly during the steps of 'Assisting' smokers for a quit attempt and 'Arranging' for a follow-up contact process ${ }^{21}$.

A shortage of skills and knowledge, limited time, high workload and limited self-confidence in regards to tobacco prevention counseling, have been previously noted among $\mathrm{GP}^{22}$. Furthermore, inadequate training, lack of incentives and reimbursement, may further contribute to the low level of 
engagement in smoking cessation actions ${ }^{17,18}$. Health care system organizational barriers and limited economic incentives, for the promotion of tobacco cessation counseling, may also enhance the 'inertia' of the physicians ${ }^{24}$. On the other hand, physicians as societal role players may influence smoking cessation outcomes as research among French Gpshas indicated limited efficacy of French physicians within smoking cessation as a result of their own high smoking rates ${ }^{25}$. This finding could be aligned to the observation that if $40 \%$ of Greek doctors are smokers ${ }^{26}$ many may have reduced motivation to deal with smoking cessation in clinical practice.

Most smokers contemplate quitting hence tobacco control efforts and policies could strengthen the transition between contemplation and an actual quit attempt ${ }^{27}$. This should trigger an alert for health policy makers, in order to expand a supportive environment through smoking cessation services. Unfortunately, organized smoking cessation services in the Greek National Health System are limited to some urban structures of secondary and tertiary health care, thus not easily accessible by residents of rural and remote areas. This situation empowers the so called 'forgotten smokers', who have the general motivation to quit but do not have access to organized and specialized services, remaining thus without essential support ${ }^{28}$. In this direction, group counselling may be a potential solution, as research has indicated that group counselling in a health care setting may be the most successful type of intervention in supporting smokers in disadvantaged areas to quit ${ }^{29}$.

Another important finding of this study is that six out of ten smokers reported a low net income per month. Increased taxation has been demonstrated as an effective method to reduce or aid quit attempts in the general population but there is evidence suggesting that these increases are ineffective at reducing income-based disparities in smoking prevalence ${ }^{30}$. Financial stress in conjunction with nicotine addiction consist a strong barrier for low-income smokers to overcome and despite the increased tobacco taxation, smoking prevalence in this population in Greece is still very high. Taking into account the above it is even more imperative to implement innovative policies for low-income smokers, in order to achieve increased cessation rates ${ }^{31}$.

The current study identified interesting regional associations between smoking characteristics and tobacco tax increases, among a limited sample of PHC patients in Northern Greece. However, we must note that this study is limited by its study design, sample size and generalizability to the population. Further research with larger population groups generalizable to patients who visit PHC services in Greece is hence warranted.

\section{CONCLUSION}

In conclusion, rural areas 'host' many heavy smokers with a low socioeconomic status who have little intention to quit. This finding stresses the need for action in the context of primary care. Smoking cessation and prevention counseling should be a priority in the educational agenda of general practice in Greece. A possible implication of this study is that GPs might and should take a more active role in assisting their patients who wish to quit smoking.

\section{REFERENCES}

1. Azagba S, Sharaf M. Cigarette taxes and smoking participation: evidence from recent tax increases in Canada. Int J Environ Res Public Health. 2011 May;8(5):1583-600.

doi: 10.3390/ijerph8051583

2. Tsalapati K, Vardavas CI, Athanasakis K, Thireos E, Vozikis A, Pavi E, Behrakis P, Kyriopoulos I. Going up in ashes? Smoking-attributable morbidity, hospital admissions and expenditure in Greece. Eur J Public Health. 2014 Mar 27.

doi: 10.1093/eurpub/cku040

3. He P, Yano E. Tobacco companies are booming despite an economic depression. Tob Induc Dis. 2009 Jun 15;5(1):9.

doi: 10.1186/1617-9625-5-9.

4. Sussman S, Levy D, Lich KH, Cené CW, Kim MM, Rohrbach LA, Chaloupka FJ. Comparing effects of tobacco use prevention modalities: need for complex system models. Tob Induc Dis. 2013 Jan 22;11(1):2.

doi: 10.1186/1617-9625-11-2

5. Vardavas CI, Filippidis FT, Agaku I, Mytaras V, Bertic M, Connolly GN, Tountas Y, Behrakis P. Tobacco taxation: the importance of earmarking the revenue to health care and tobacco control. Tob Induc Dis. 2012 Dec 27;10(1):21.

doi: 10.1186/1617-9625-10-21

6. World Health Organization. WHO Report on the Global Tobacco Epidemic; World Health Organization: Geneva, Switzerland, 2008. Available at: http://www.who.int/tobacco/mpower/mpower_ report_full_2008.pdf (accessed 10 February 2016)

7. Choi K, Boyle RG. Minnesota smokers' perceived helpfulness of 2009 federal tobacco tax increase in assisting smoking cessation: a prospective cohort study.BMC Public Health. 2013 Oct 18;13(1):965.

doi: 10.1186/1471-2458-13-965

8. Scollo M, Hayes L, Wakefield M: What price quitting? The price of cigarettes at which smokers say they would seriously consider trying to quit. BMC Public Health 2013, 13:650.

doi: 10.1186/1471-2458-13-650

9. MacFarlane K, Paynter J, Arroll B, Youdan B: Tax as a motivating factor to make a quit attempt from smoking: a study before and after the April 2010 tax increase. J Prim Health Care 2011, 3(4):283288.

10. Centers for Disease Control and Prevention: Decrease in smoking prevalence - Minnesota, 1999-2010. MMWR Morb Mortal Wkly Rep 2011,60(5):138-141.

11. Godfrey C, Maynard A. Economic aspects of tobacco use and taxation policy. BMJ 1998;297:339-43.

12. http://www.who.int/fctc/reporting/party_reports/greece_annex1_ the_greek_tobacco_epidemic_2011.pdf (The Greek Tobacco Epidemic). (assessed 10 February 2016). 


\section{Short Report}

13. Joossens L, Lugo A, La Vecchia C, Gilmore AB, Clancy L, Gallus S. Illicit cigarettes and hand-rolled tobacco in 18 European countries: a cross-sectional survey. Tob Control. 2014 May;23(e1):e17-23. doi: 10.1136/tobaccocontrol-2012-050644. Epub 2012 Dec 10.

14. Sutton S, Smith S, Jamison J, Boase S, Mason D, Prevost AT, Brimicombe J, Sloan M, Gilbert H, Naughton F. Study protocol for iQuit in Practice: a randomised controlled trial to assess the feasibility, acceptability and effectiveness of tailored web- and textbased facilitation of smoking cessation in primary care. BMC Public Health. 2013 Apr 10;13:324.

15. Strayer SM, Heim SW, Rollins LK, Bovbjerg ML, Nadkarni M, Waters DB, Hauck FR, Schorling JB. Improving smoking cessation counseling using a point-of-care health intervention tool (IT): from the Virginia Practice Support and Research Network (VaPSRN). J Am Board Fam Med. 2013 Mar-Apr;26(2):116-25.

16. Douglas L, Szatkowski L. Socioeconomic variations in access to smoking cessation interventions in UK primary care: insights using the Mosaic classification in a large dataset of primary care records. BMC Public Health. 2013 Jun 5;13:546.

17. Twardella D, Brenner H. Lack of training as a central barrier to the promotion of smoking cessation: a survey among general practitioners in Germany. Eur J Public Health. 2005 Apr;15(2):140-5.

18. Keogan S, Burns A, Babineau K, Clancy L. Dental Practitioners and Smoking Cessation in Ireland. Tob. Prev. Cessation 2015;1(October):5 doi : /10.18332/tpc/59482

19. Vardavas CI, Symvoulakis EK, Lionis C. Dealing with tobacco use and dependence within primary health care: time for action. Tob Induc Dis. 2013 Feb 26;11(1):6.

doi: 10.1186/1617-9625-11-6

20. Piper ME, Baker TB, Mermelstein R, Collins LM, Fraser DL, Jorenby DE, Smith SS, Christiansen BA, Schlam TR, Cook JW, Oguss M, Fiore MC. Recruiting and engaging smokers in treatment in a primary care setting: developing a chronic care model implemented through a modified electronic health record. Transl Behav Med. 2013 Sep;3(3):253-63. doi: $10.1007 / \mathrm{s} 13142-012-0178-8$

21. Centers for Disease Control and Prevention. Quitting smoking among adults - United States 2001-2010. MMWR. 2011;60:15131519.

22. Goldstein MG, DePue JD, Monroe AD, et al. A population-based survey of physician smoking cessation counseling practices. Prev Med 1998;27(5 Pt 1):720 -9.

23. Eisner D, Zoller M, Rosemann T, Huber CA, Badertscher N, Tandjung R. Screening and prevention in Swiss primary care: a systematic review. Int J Gen Med. 2011;4:853-70. ]

24. Von dem Knesebeck O, Hoehne A, Link C, Marceau L, Adams A, Roland M, Campbell S, Siegrist J, McKinlay J. Talking about smoking in primary care medical practice--results of experimental studies from the US, UK and Germany. Patient Educ Couns. 2012 Oct;89(1):51-6. doi: 10.1016/j.pec.2012.04.011

25. Josseran L, King G, Guilbert P, Davis J, Brücker G. Smoking by French general practitioners: behaviour, attitudes and practice. Eur J Public Health. 2005 Feb;15(1):33-8.

26. Goumas GS A cigarette, doctor? ... No thanks! Hellenic J Cardiol. 2013 May-Jun;54(3):157-8.

27. Thyrian JR, Panagiotakos DB, Polychronopoulos E, West R, Zatonski W, John U. The relationship between smokers' motivation to quit and intensity of tobacco control at the population level: a comparison of five European countries. BMC Public Health. 2008 Jan 3;8:2. doi: 10.1186/1471-2458-8-2.

28. Uppal N, Shahab L, Britton J, Ratschen E. The forgotten smoker: a qualitative study of attitudes towards smoking, quitting, and tobacco control policies among continuing smokers. BMC Public Health. 2013 May 3;13:432. doi: 10.1186/1471-2458-13-432.

29. Benson F, Nierkens V, Willemsen M, Stronks K. Effects of different types of smoking cessation behavioural therapy in disadvantaged areas in the Netherlands: an observational study. Tob. Prev. Cessation 2016;2(February):4 doi: $10.18332 / \mathrm{tpc} / 61616$

30. Farrelly M.G., Nonnemaker J.M., Watson K.A. The consequences of high cigarette excise taxes for low-income smokers. PLoS ONE. 2012;7 doi: 10.1371/ journal.pone.0043838

31. Widome R, Joseph AM, Hammett P, Van Ryn M, Nelson DB, Nyman JA, Fu SS. Associations between smoking behaviors and financial stress among low-income smokers. Prev Med Rep. 2015 Oct 29;2:911-5. doi:10.1016/j.pmedr.2015.10.011

\section{ACKNOWLEDGEMENTS}

We would like to thank $\mathrm{Dr}$. G. Kounis for performing the statistical analysis of the data.

CONFLICT OF INTEREST

The authors have completed and submitted the ICMJE Form for Disclosure of Potential Conflicts of Interest and none were reported.

\section{FUNDING}

There was no source of funding for this research.

\section{AUTHORS'}

CONTRIBUTIONS

EKS, SK and NK conceived the idea, designed the study and contributed to manuscript preparation and data interpretation. DK and SK carried out data collection. CIV also contributed to data interpretation. EKS, CV and $\mathrm{CL}$ offered technical and intellectual input and revised the manuscript. All authors have read and approved the final manuscript.

\section{PROVENANCE AND PEER} REVIEW

Not commissioned; externally peer reviewed. 